Long Island University

Digital Commons@LIU

Brooklyn Library Faculty Publications

Library

2016

\title{
Toward the Resistant Reading of Information: Google, Resistant Spectatorship, and Critical Information Literacy
}

Eamon Tewell

Long Island University, eamon.tewell@liu.edu

Follow this and additional works at: http://digitalcommons.liu.edu/brooklyn_libfacpubs

Part of the Library and Information Science Commons

\section{Recommended Citation}

Tewell, Eamon, "Toward the Resistant Reading of Information: Google, Resistant Spectatorship, and Critical Information Literacy" (2016). Brooklyn Library Faculty Publications. Paper 17.

http://digitalcommons.liu.edu/brooklyn_libfacpubs/17 


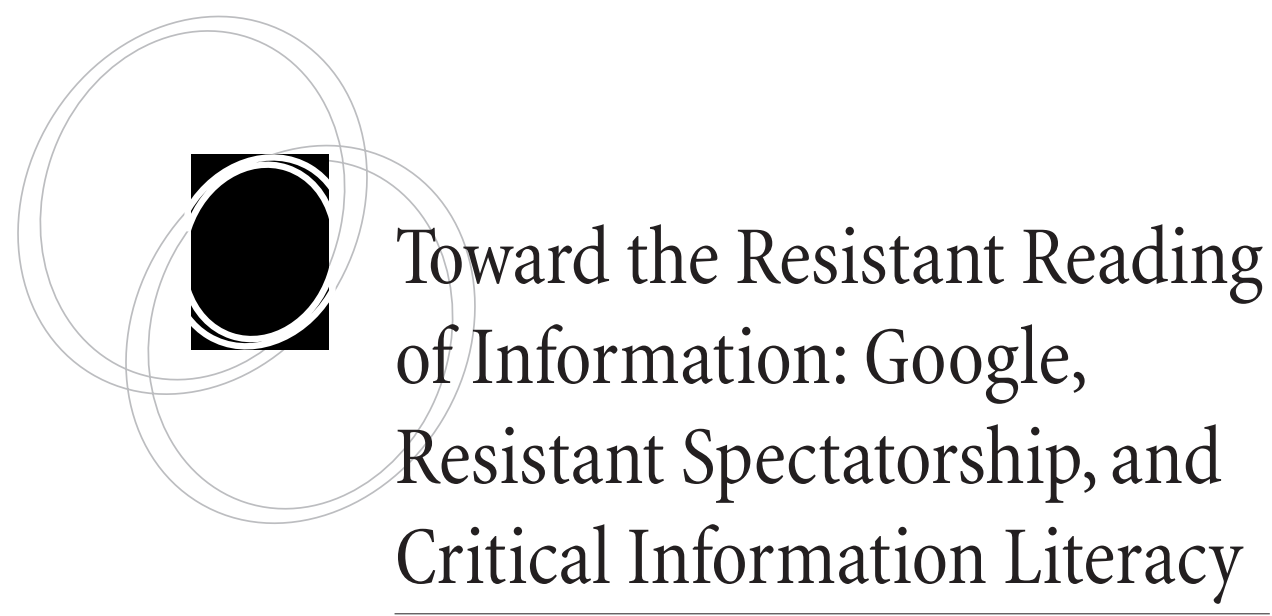

Eamon Tewell

abstract: The theory of resistant spectatorship posits that individuals interacting with media and information may have the agency or power to oppose, reject, or reassemble the message they encounter instead of passively accepting it. This study puts resistant spectatorship in conversation with information literacy and critiques one example of a dominant information discovery system, Google Search, from a "resistant" position. Additionally, this study argues that, within academic libraries, the practice of critical information literacy, a pedagogical approach aligned with the concept of resistant spectatorship, is an ideal mode for encouraging students to become resistant readers of information in its increasingly corporate-mediated forms.

\section{Introduction}

A s information landscapes continue to shift, the intensifying corporate ownership, production, and dissemination of information necessitate a response from the library profession. Siva Vaidhyanathan characterizes the current information landscape as a tangled thicket generally consisting of "stable, localized hierarchical outlets," such as libraries and commercial publishers; user-created sources such as Wikipedia and blogs; and "hypercommercialized, data-mined, advertising-directed platforms" such as Google. ${ }^{1}$ Information access has become of utmost importance socioeconomically, yet this transition has largely occurred according to the imperatives of corporate hegemony and private profit. ${ }^{2}$ This complex information landscape is moving toward an increasingly commoditized digital environment, and, in particular, one that intentionally positions technology as politically neutral and unencumbered with human values. Yet it is important to recognize that no information service, from reference desks staffed by 
librarians to complex search algorithms, is unbiased in its delivery of material, as much as it may want to appear so for reasons of professional legitimization or to encourage passive acceptance. By failing to explicitly recognize the ideological functions of com-

It is important to recognize that no information service, from reference desks staffed by librarians to complex search algorithms, is unbiased in its delivery of material, as much as it may want to appear so. mercial content providers, librarians lose the ability to show to students the current information landscape as what it is: dominated by search engines and other corporate-owned media that operate under a veneer of neutrality. Most significantly, this lack of recognition makes it difficult for learners to understand that they can and should resist such sources, and that these technologies should be regarded as critically as any other.

It is difficult to discuss contemporary information-seeking without considering Google. Google is not only the conduit for a massive portion of online searching but also increasingly the lens through which Internet users view their world, whether through Google Images, Street View, or YouTube. Google Search is a prime example of a depoliticized digital technology that users encounter and engage with billions of times per day. Search engines have, after all, become what Michael Zimmer calls "the center of gravity for people's everyday information-seeking activities," and Google is the prevailing resource for accessing a vast majority of online content. ${ }^{3}$ As Safiya Noble observes, Google has become an important subject of study due to the dominance it exerts in directing users to information, whether by answering questions directly or by guiding them to other websites. Google also requires study, she adds, because of "the near-universality with which Google has been adopted and embedded into all aspects of the digital media landscape."4 Amber Davisson points out that relying on any one perspective will obscure the full picture. Regardless of a company's stated intentioneven if the slogan is "don't be evil" — there is danger in letting one source so thoroughly shape the information we find and how it is retrieved. ${ }^{5}$ What does it mean to allow one company to determine what we know about the world?

The theory of resistant spectatorship asks us to consider alternatives to our too frequently uncomplicated interactions with media technologies and the companies that manufacture them, as well as to reevaluate the information supplied by these providers. First introduced by cultural theorist Stuart Hall in 1973, resistant spectatorship recognizes that an individual interacting with a media object, such as a televised newscast, may choose to "read" it from one of three positions: dominant, negotiated, and oppositional. A dominant position means that the media text is interpreted according to the meaning intended or preferred by its creators, resulting in limited misunderstanding between the message and the readers because they share an acceptance of the dominant ideology. A negotiated position means that the readers choose to distance themselves from the text in some ways but not others, so that both dominant and oppositional elements come into play - the basic premise of an argument may be accepted, but the readers are not willing to accept it in full and modify the meaning in some way that reflects their own selves and interests. Thirdly, readers can resist the text and refuse its intention by 
deconstructing, reconstructing, or outright rejecting the message as it is received and supplying their own interpretation. The intended message is understood but is opposed, and the readers substitute and create their own meaning from the text. This oppositional position is that of resistant spectatorship because it challenges dominant cultural beliefs as they are presented and reads a text against itself. Hall's theory is noteworthy in that it explicitly puts the viewer in a position of potential agency or power and recognizes not only that individuals are far from passive receptacles for messages from mass media but also that all texts hold multiple meanings. Further, resistant spectatorship acknowledges that media is decoded in culturally situated contexts and that one's interpretation of a message is necessarily dependent upon one's personal identity and lived experiences, including race, class, gender, and sexuality.

Applied to the sphere of academic librarianship, resistant spectatorship can be extrapolated from visual media to information in general to gain a better understanding of the deeply contextual nature of students' engagement with information. A resistant engagement means that learners should not and do not accept messages blindly; that is, they should evaluate and consider the information presented to them based on their own experiences and understandings, with the intent of thinking more critically regarding such facets as authorship, production, and bias. In locating and reading a journal article, for example, a student may accept the entirety of what the article presents (a dominant reading), may accept the study's general argument but disagree with other

\section{A resistant engagement means that learners should not and do not accept messages blindly; that is, they should evaluate and con- sider the information presented to them based on their own expe- riences and understandings.} points (a negotiated reading), or may reject the article altogether and substitute another interpretation (a resistant reading). This scenario can take place vis-à-vis any engagement with information. What is important is not necessarily the specifics of what students do with this material—-they may refer to an article they fundamentally resist because the constraints of their assignment call for it-but that they develop a heightened capacity to "read" the information they encounter, ranging from a book to a Facebook post, from a negotiated or resistant position as they see fit and on their own terms. The concept of resistant spectatorship in relation to information becomes complicated when major content sources and providers position their services, methods, or ideologies as impartial. Google Search accomplishes this through a variety of means, from its blank white homepage to the consistent claim that its algorithms determine what appears and what does not, independent of human influence.

The concept of neutrality also operates in the library profession. The professional discourse frequently invokes neutrality as a key characteristic of the field as a means to prevent the questioning of hegemonic political and economic forces. This contention allows the library to continue acting as an enforcer of the status quo. Information literacy (IL), a concept central to academic librarianship, has stood at the forefront of revitalizing instruction in library settings. Yet information literacy as it is currently conceived lacks the politicized understanding of information environments that is necessary to comprehend 
how corporations such as Google shape how we see information, and by extension, our world. Critical information literacy refutes the neutrality of traditional IL and asks library educators and students to engage with the social and political dimensions of information, including its production, dissemination, and reception. In this way, critical information literacy puts the ideas behind resistant spectatorship into practice and encourages learners to not only be skeptical of but also to understand and potentially resist dominant information modes. This study, then, will examine Google Search and consider how the theory of resistant spectatorship allows us to better understand individuals' relation to contemporary information environments. This study also will propose critical IL as a practice aligned with the principles of resistant spectatorship that allows librarians and students to recognize and act upon oppressive information structures.

\section{Neutrality in Contemporary Information-Seeking}

In his prescient consideration of information inequality within the emerging information society, Herbert Schiller perceived the shift of information to a commodity that is packaged and sold by corporations, which shrug off expectations of transparency and

Though far from being a new development, this shift in the ownership of information from publicly available material to a privatized commodity in the hands of businesses leads to corporate speech becoming a dominant discourse on national and international levels. accountability. Though far from being a new development, this shift in the ownership of information from publicly available material to a privatized commodity in the hands of businesses leads to corporate speech becoming a dominant discourse on national and international levels. This same discourse obscures independent voices. ${ }^{6}$ The shift from state to private power in the realm of information means, Schiller adds, that these corporations must assert that their "message- and image-making activity is a daily exercise

in free expression" independent from the restrictive nature of the state. ${ }^{7}$ Moreover, some categories of content, such as academic journal articles published by commercial interests, simultaneously produce immense profit and take on value as corporations seek to monetize this information. As a result, he explains, "What had been in large measure a social good has been transformed into a commodity for sale." ${ }^{8}$ The Internet as a medium has not only rendered traditional media channels increasingly obsolete by offering improved modes of distribution for companies but also has created new media types that are more social and interactive. Corporate control over access to and discovery of myriad types of information has expanded to an unparalleled global scope. Once-fledgling companies, in particular commercial search engines based in the United States, have amassed areat deal of ideological power with the advent of the Internet. Accompanying this power is a tremendous influence upon how content is indexed, included, prioritized, or excluded, including setting expectations for how online information retrieval functions will evolve. This influence becomes especially problematic when commercial search engines become so dominant a force. As Noble observes, "Cuts to public education, public libraries, and 
community resources only exacerbate our reliance on technology, rather than information and education professionals, for learning." ${ }^{\prime 9}$

A reliance on technology, while not necessarily an issue in itself, becomes one when it is shrouded in the carefully articulated rhetoric of neutrality that obscures how it reflects and reinforces existing power structures. New technologies are frequently positioned not only as unbiased but also as a means to connect people of diverse backgrounds and allow individuals to reconsider cultural divides by accessing a range of viewpoints. This argument for search technologies' capacity for fostering alternate views quickly falters when one considers the "filter bubble," the customized search results produced when search engines apply personalization features to show only content expected to interest the user. As a result, users become disconnected from news and stories that might be disagreeable or different. ${ }^{10}$ Alison Hicks observes that, contrary to this widely held belief of the Internet as a culturally democratic force, it has the strong capacity to reinforce biases. This capability "can be seen most clearly in the design of tools, for example, algorithms that are weighted towards their designers' biases or search engine personalization trends that narrow our information experiences." 11 The design, deployment, and use of technological tools are necessarily subject to the same biases, discrimination, and power structures present in society.

The facade of neutrality constructed by search engines is not unique to this technology. Choices made in the development of any "universal" organizational or discovery system will inevitably reflect the biases of those responsible for creating and maintaining the systems. An example of such biases in libraries is the major classification structures for their collections: Library of Congress Classification, Library of Congress Subject Headings, and the Dewey Decimal System. As an example of these biases, Emily Drabinski describes a classroom discussion on how the Library of Congress Subject Headings for African American women have changed over the years. The white supremacy inherent in this classification system is thrown into sharp relief when a student asks, as a researcher interested in the history of white women, whether they need to search specifically for "white" in the subject headings. The answer is no, pointing to an assumption of universal whiteness. ${ }^{12}$ Key to the construction of neutrality in contemporary information-seeking are algorithms, which form the core of online information retrieval. Algorithms provide a convenient culprit quickly invoked by engineers when discovery systems commit an "error" that is in fact a reflection of sexism, racism, homophobia, or other type of discrimination, as has been uncovered by researchers and everyday information seekers alike.

Algorithms have an increasingly central role in the information landscape because they govern the terms under which content is presented to users via search engines and they are used to make innumerable other decisions, from policing to health care. This determination of relevance by search algorithms allows users to navigate anywhere from individual databases to the entire Internet. Algorithms not only help users find information, Tarleton Gillespie notes, but also, more broadly, they "provide a means to know what there is to know and how to know it, to participate in social and political discourse, and to familiarize ourselves with the publics in which we participate."13 Thus, the stakes for algorithms are exceptionally high and only increase as algorithms-typically patented, proprietary, and closely guarded pieces of intellectual property-continue to mediate search experiences on mass levels. 
Algorithms fulfill both practical and ideological functions to assuage fears of overreliance on technology, especially a technology such as Google Search that is designed to operate as a black box. The widespread trust put into search engines can be viewed as a manifestation of the public's belief in the neutrality of technology and its unawareness

The widespread trust put into

search engines can be viewed as a manifestation of the public's belief in the neutrality of technology and its unawareness of the social values that are part and parcel of any piece of technology's design. of the social values that are part and parcel of any piece of technology's design. ${ }^{14}$ The very operation of algorithms is an exercise in trust as users anticipate and receive reassurance that the outcomes of an algorithm are accurate, impartial, and legitimate. As a practical and political tool, the providers of algorithms create the illusion that these complex formulas are "automatic" and free from attempted influence. Gillespie delineates the function of algorithmic objectivity as such:

"The careful articulation of an algorithm as impartial ... certifies it as a reliable sociotechnical actor, lends its results relevance and credibility, and maintains the provider's apparent neutrality in the face of the millions of evaluations it makes." 15 This duality of algorithms means that they can be defended as lacking human agency when the results are challenged and simultaneously promoted to advertisers as a tool to better target and reach consumers, the latter being particularly important for companies like Google that generate a massive portion of their revenue from advertising. Importantly, algorithmic logic does not always operate the way its designers intend and can have unintended outcomes and consequences. Just as any media reflects and responds to societal positions, technological neutrality appears as such not only by design but also as a result of what Gillespie calls "the mundane realities of news cycles, press releases, tech blogs, fan discussion, user rebellion" and competitors. ${ }^{16}$

Even when the Internet was in its infancy, people understood that it would become far too large to navigate without assistance, and moreover, that users were often unwilling to look beyond the first ten search results. These understandings led to search engines developing a myopic focus upon delivering the "best" results, which requires decisionmaking regarding what constitutes a good result and also leads to a focus on controlling data to deliver such results. Google and other major commercial search companies' processes are, as Noble states, "based on identifying and assigning value to various types of information through web indexing [and] complex mathematical formulations are developed into algorithms that are a part of the automation process," which is now compulsory for such content providers. ${ }^{17}$ But these search engines fail to take social and historical context into account. Narratives that direct conversations on online searching invoke objectivity and popularity as the ultimate decision-making criterion, while the myth of digital democracy (symbolized by Google Search) means that not only do users legitimize and consent to the practices of a search engine through its use but also they become accustomed to the appearance of misogynist and racist results.

Recent works have established that Google Search can promote damaging racial, gender, and cultural stereotypes. The search engine normalizes these stereotypes by 
virtue of presenting them in search features and results, especially in Autocomplete, the feature that automatically predicts the remaining characters in a word or phrase based on what has been typed or input before. Bess Sadler and Chris Bourg note that not only does Google Search present a near-totalizing point of view on questions of relevancy and significance, thereby perpetuating existing systems of inequity, but also software created in environments hostile toward underrepresented groups is bound to result in further discrimination, intentional or not. ${ }^{18}$ With these criticisms in mind, the discussion will turn to an analysis of Google Search, including issues of surveillance, the implications of where a site appears in search rankings for a particular query, racial and gender discrimination, damaging stereotypes, and concerns regarding personalization.

\section{The Dominant Information Structures of Google Search}

When Eric Schmidt, then Google's chief executive officer, discussed his ultimate goals for the search engine, Amber Davisson reports, "He foresaw the day when the site would be able to answer abstract questions, be able to answer hypothetical questions, and eventually be able to anticipate our questions." ${ }^{19}$ This direction of the company means that the original intent of helping users find content online was in fact a project much larger than its search-oriented beginnings inferred; Google envisioned not-so-subtly guiding people's choices and interactions with the world from early on. The company's intentions conflict with the public's trust in Google and the myth of digital democracy. A 2012 Pew Internet \& American Life survey illustrates Americans' generally positive attitudes toward search engines. Results of the survey indicate that, on the whole, respondents disapprove of search engines collecting data about them to determine their search results or deliver targeted advertisements. Sixty-five percent of respondents agreed with the statement "It's a bad thing if a search engine collected information about your searches and then used it to rank your future search results, because it may limit the information you get online and what search results you see." Seventy-three percent indicated they would "not be okay with a search engine keeping track of your searches and using that information to personalize your future search results" because it is an invasion of privacy. Many search users disapprove of personal data being collected for search results or for advertising purposes. Despite these reservations, overall views of search engine performance are favorable, with 66 percent of users saying search engines are a fair and unbiased source of information. At the same time, only 38 percent of Internet users claim to know of ways they could limit how much data about them a website collects. As continues to be the case years after the survey was conducted, Google was the most used search provider, with 83 percent of respondents utilizing it for online searching. ${ }^{20}$

Alejandro Diaz posits three questions that have historically been asked of traditional media but are infrequently applied to technologies like search engines: Can underrepresented voices and diverse viewpoints be heard through the filter of search engines? What role does advertising play in the returned results? Do a few players dominate the industry? ${ }^{21}$ An increasing number of scholars have taken up these lines of inquiry. When applied to Google, these questions surface a number of important critiques, ranging from a business model based on detailed surveillance of users to harmful search results in Google Images and Autocomplete that are chalked up to algorithmic dysfunction. 
Underlying each major critique is the fact that dominant search engines both mask and maintain what Noble calls "the unequal access to social, political, and economic life in the United States as broken down by race, gender, and sexuality." In addition, the commercial nature of search puts paid advertising and Google's own products and interests at the top of the page, thus determining search results. ${ }^{22}$ While a corporation prioritizing its bottom line without concern for social equality is far from a novel practice, it does not receive enough attention considering Google's centrality to the contemporary information landscape. The first of these critiques concerns issues of surveillance.

A core component of Google's stated mission to organize the world's information has been the company's quest to create the perfect search engine, which has resulted in the detailed monitoring and collection of data pertaining to users' online activities. ${ }^{23}$ Zimmer refers to such digital spying as "dataveillance." He says, "These search-based infrastructures of dataveillance contribute to a rapidly emerging 'soft cage' of everyday digital surveillance, where they, like other

The understanding of people's habits only improves when they create a Google account and use it to utilize Google's wide suite of products, which range from e-mail to maps. Google encourages this practice not only so that users may receive a customized experience but also so that Google may amass more data to tweak algorithms and target advertising more effectively. dataveillance technologies before them, contribute to the curtailing of individual freedom, affect users' sense of self, and present issues of deep discrimination and social justice." ${ }^{24}$ Google's first press release clearly stated the company's ultimate ideal: "A perfect search engine will process and understand all the information in the world ... That is where Google is headed." Larry Page, Google's cofounder, also notes this conception of the perfect search engine, stating, "The perfect search engine would understand exactly what you mean and give back exactly what you want." ${ }^{25}$ Google has determined that the best way to achieve such a goal is through the collection of as much data about its users as possible. This practice of "dataveillance" allows for the "perfect recall" of the searcher's identity and interests based on prior activities. The understanding of people's habits only improves when they create a Google account and use it to utilize Google's wide suite of products, which range from e-mail to maps. Google encourages this practice not only so that users may receive a customized experience but also so that Google may amass more data to tweak algorithms and target advertising more effectively. Thus, Google amasses and maintains the server logs of user behavior, including details ranging from the text of basic search queries to individuals' locations.

Google informs users that collecting exhaustive data on their behavior is helpful for personalization and is de facto practice among commercial search engines. That is true for the most part, apart from notable exceptions such as DuckDuckGo, a search engine that claims to protect users' privacy and avoid the filter bubble. Search engines are less willing to divulge that their motivation to collect user data is financially motivated. Having access to a person's e-mail along with the ability to edit online documents, for 
instance, will likely increase a user's allegiance to a particular provider. Such allegiance both increases exposure to advertisers on that service and makes it more likely for the user to subscribe to fee-based services. Google's suite of products not only extends its panoptic gaze but also utilizes them in what Zimmer calls the "profiling and categorization of a user's potential economic value" to then sell to advertisers. ${ }^{26}$ By placing any user of Google's services under an almost invisible gaze, this extensive infrastructure of "dataveillance" results in an expectation regarding the divulgence of personal data that is routinized, internalized, and extended to other aspects of users' lives. This sense of inescapability, combined with its relative invisibility and the expectations that it creates, is the most damaging aspect of Google's practices of "dataveillance." It limits inquiry into and understanding of the world-now increasingly occurring solely in digital spaces-that are necessary for personal awareness and public participation. Moreover, the collection of data regarding personal online activities naturalizes mass surveillance, contributing to a growing environment of discipline and social control.

Google's legendary search landing page is one instance of the tension between the company's painstakingly designed products and the complicated realities and decisions being made that go into the search results. Upon visiting Google's homepage, users find a white, mostly blank page, containing a cheerful logo and a single search box. The white background is an important design choice, signifying a type of neutralized blank slate, seemingly open to locating whatever the searcher wishes to find and passing no judgment. The white background combined with the colorful and interactive Google logo, often based on historical figures' birthdays or current events, allows Google to temper the appearance of stark objectivity with its carefully constructed facade of playfulness and fun. There is no prompt for an advanced search option, and the user's attention is clearly directed to the search box. The simple design belies the many interventions made in delivering content so quickly and with such precision. Google Search, Vaidhyanathan observes, not only filters our information needs and focuses them through technology such as Autocomplete but also does so efficiently and in such a clean and navigable list that it provides the comforting illusion of both comprehensiveness and accuracy. As a result, says Vaidhyanathan, "Its process of collecting, ranking, linking, and displaying knowledge determines what we consider to be good, true, valuable, and relevant." 27 Google's acts of rendering the world of digital Google's acts of rendering the world of digital information findable and judging relevance are far messier than the interface would make them seem. information findable and judging relevance are far messier than the interface would make them seem. Personalization is another factor with serious implications for how people view and use online content.

Google began use of personalization algorithms starting in 2009 with the intent of tailoring users' search experiences and results while simultaneously gathering valuable data about their activities. Data captured at the individual user level include where people $\log$ in from, the browser they use, and the time it takes them to select a link after typing in search terms, among potentially dozens of other data points. ${ }^{28}$ Rather than a service for users, personalization acts as a tool for categorizing people-users are matched to 
a certain profile or group based on their data, and this information is used to match consumers with advertisers. ${ }^{29}$ Moreover, the opacity of the customization process makes it difficult to know how the results we see are affected by what Google thinks we want to know. This disrupts the conception of the Web as a place for conversation among varying views. The creation of the filter

The filter bubble is significant in that it not only uses private information without requiring an individual's awareness but also limits the range of views that a person may come into contact with by supplying only content with which the user will likely agree. bubble is significant in that it not only uses private information without requiring an individual's awareness but also limits the range of views that a person may come into contact with by supplying only content with which the user will likely agree. This is problematic because of its implications for learning, which can only occur when learners encounter ideas or things they were not previously aware of, had not understood, or had never considered. Google's personalization filter, Vaidhyanathan explains, "shields

the searcher from such radical encounters with the other by 'personalizing' the results to reflect who the searcher is, his or her past interests, and how the information fits with what the searcher has already been shown to know," characteristics diametrically opposed to the process of learning. ${ }^{30}$ The effect is potentially one of undermined public knowledge and political dialogue.

There are ways to uncover the biased processes of Google Search and its algorithms, as Safiya Noble's work on the representation of African American girls in Google makes clear. Through conducting keyword and image searches for "black girls," she discovered a commercial co-optation of black female identity. Many websites on the first page of search results were pornographic, while Google Images revealed other highly sexualized images. The impact on young girls looking online for information about their identities is obvious. "Google results on the words 'black girls' discursively reflect hegemonic social power and racist and sexist bias," Noble states, while Google chooses to serve "the interests of its commercial partners and advertisers, rather than rendering the social, political and economic interests of Black women and girls visible." ${ }^{31}$ A study by Latanya Sweeney investigates whether black-sounding names are associated with online ads suggesting an arrest record more often than white-sounding names when searched on Google and Reuters.com. ${ }^{32}$ The consequences are serious, not least because someone may search an individual's name when considering that person for a job or other opportunity. Further complicating matters, these same ads suggesting arrest records may not appear for others competing for the same job. Sweeney's findings unambiguously detected racial discrimination in the delivery of these ads. Though it is difficult to learn who is at fault, the responsibility ultimately lies with Google and its methods for the generation of ad revenue.

In their research into damaging stereotypes in Google's Autocomplete function, Paul Baker and Amanda Potts draw attention to Hall's positions of the spectator, noting that this "notion of dominant, oppositional and negotiated resistant readings indicates that 
audiences potentially have complex and varying reactions to a particular 'text.'"33 By entering different combinations of question words and identity terms-such as "why are blacks..." - the authors elicited Autocomplete suggestions about stereotypes regarding various social groups. Baker and Potts found that Google's Autocomplete inadvertently reproduces stereotypes through its production of suggested terms that are racist, sexist, and homophobic. Google Search fails to offer an easy method for "resistant readers" to flag Autocomplete suggestions as offensive, a function offered by many other websites. To do so would disrupt the illusion of Google's interface as a neutral tool, when, in actuality, Google seems to find it worth intervening in search results only to protect its commercial interests.

Given these numerous issues with Google Search and the dominance of the company over the existing information landscape, the question of how one might begin to resist the content provider's hegemonic narratives shrouded in technological neutrality becomes essential. To begin, one must understand how Google works and situate this knowledge within one's own experiences of information as it is encountered. Davisson suggests developing "a critical perspective that emphasizes human motive in the engineering process," one that provides an awareness of both technical limitations and human biases. ${ }^{34}$ Educational initiatives

Google's Autocomplete inadvertently reproduces stereotypes through its production of suggested terms that are racist, sexist, and homophobic. in digital literacy are one way this might be accomplished, as Internet users could learn to think critically about how the information they access is produced and made available. Additionally, Davisson advocates dialogue surrounding the use of search engines, including critically comparing search engine experiences and reflecting upon how and why search engines work. It is important to incorporate this understanding into everyday Internet experiences because the questions and manifestations of trust, control, and power addressed in this section are enacted on a massive scale. Instead of asking whether Google controls and manipulates us, we must ask whether we (and Google) can do better. Is Google's system of organizing and making accessible the world's information ideal for all parts of the world, or does it serve to benefit only some segments of society? Does the system give us choices, or are our choices already determined ${ }^{35}$ A greater understanding of the complexities behind the act of typing a few words into Google's search interface is necessary. Toward this understanding, the theory of resistant spectatorship is a useful way of comprehending people's engagement with information as a personal, contextualized, and potentially contested interaction. Likewise, the practice of critical IL encourages librarians to teach in a way that recognizes the political and social underpinnings of information structures

Instead of asking whether Google controls and manipulates us, we must ask whether we (and Google) can do better. and supports learners' agency in the educational process. The following section presents an alternative to hegemonic constructions of information, allowing the information user who appears trapped in existing systems to resist such domination. 


\section{Resistant Spectatorship in the Information Age}

The "information age," characterized by a shift from economies propelled by traditional industry to those driven by digital information, holds a number of ramifications for participants in this knowledge-based environment. The names information age or information society problematically suggest that we have progressed into an era more equitable than and separate from the past. These terms imply that information is bountiful and accessible by all, a misleading proposition considering inequalities in the United States and globally. Given information's position as the preeminent commodity of present-day capitalism, Cathy Eisenhower and Dolsy Smith observe:

The finessing of information occupies more and more of the labor in virtually every field [and] labor itself is turned into an informational potential ... Marx talked about laborpower in terms of time, but capital seeks subtler mechanisms to measure and absorb that power, sending its tendrils deep into the reservoirs of intelligence and personality. ${ }^{36}$

As such, our contemporary period could usefully be considered what Bernard Stiegler calls the "hyperindustrial epoch," an era in which industrialization has not ended but instead has expanded to technology that encompasses all human experience. Hyperindustrial societies embody the industrialization of all things, wherein individuals act primarily as consumers and one's time away from work is also spent working, whether for one's employer "off the clock" or by creating and curating content and thus value for social media companies. ${ }^{37}$

Using this concept of the hyperindustrial society as a basis, corporate-mediated platforms produce the vast majority of cultural information in our era and make it discoverable. This ownership of information by profit-driven entities means that the nuanced understanding of information's political and social dimensions is not just an advantage for operating in the world, but a necessity. The theory of resistant spectatorship, derived from the field of media studies, offers a unique lens through which to view the problems of information literacy and how to critically engage content, sources, platforms, and providers. Resistant spectatorship provides a more detailed picture of how people receive information and media, beginning with the premise that when an individual interacts with a message presented through a film, website, or other media, the person does not passively accept its meaning and instead may reinterpret, substitute, or entirely reject it based on personal experiences and understandings. Resistant spectatorship has particular ramifications for libraries and library instruction. The theory not only pertains to how information is received by users but also promotes the conception that information is not experienced on a one-size-fits-all basis. Resistant spectatorship encourages us to acknowledge that information-seeking and evaluation are inherently situated within raced, gendered, and classed environments, and the groups with which one identifies influence one's engagement with information. Before discussing the implications that resistant spectatorship holds for information literacy and library instruction, a description of the theory's development and primary contentions will serve as an introduction.

Authors have referred to resistant spectatorship by a number of similar phrases, all of which allude to the concept's central notion of resistance against dominant ideologies as expressed through media: counter-reading, the resisting spectator, reading against 
the grain, the oppositional gaze, or radical viewing. Resistant spectatorship theorizes that real viewers make their own decisions regarding whether to accept, negotiate, or reject a message. The theory has had great impact in film studies, where the concept of a monolithic, unengaged spectator has been challenged through studies of how working class audiences, black women, lesbians, gay men, and teenagers interact with film and television as viewers. Far from passively accepting a given message from the media, various audiences and individuals may interpret and recast an intended message to suit their own

Resistant spectatorship theorizes that real viewers make their own decisions regarding whether to accept, negotiate, or reject a message. needs and interests. The recognition of this dynamic interaction between people and media in the process of making meaning positions the viewer as one with potential agency, no longer completely powerless under the operation of the cinematic apparatus.

Resistant spectatorship is largely derived from cultural theorist Stuart Hall's immensely influential theory of the "encoding/decoding model of communication," first developed in 1973. In his essay describing the model, Hall notes that, for a message to have an effect, satisfy a need, or be put to a use, "it must first be appropriated as meaningful discourse and be meaningfully coded." Instead of describing a passive viewer who absorbs the message of all media they encounter, Hall's theory of decoding recognizes that media and information use cannot be understood in purely behavioral terms, which overly simplify the complicated process of negotiating information. These processes are themselves "produced by social and economic relations, which shape their 'realization' at the reception end." Hall proposes three stages of "reading" media texts: dominant, negotiated, and oppositional (also known as resistant). ${ }^{38}$

When a viewer decodes the meaning of a film, news segment, podcast, online video, or other media text in the way that the producer of that message intends, that individual is operating within the sphere of dominant ideology. In the negotiated position, Hall suggests that this reading "contains a mixture of adaptive and oppositional elements" and "acknowledges the legitimacy of the hegemonic definitions" while simultaneously making its own ground rules. The reader accepts the overarching assumptions of a particular text but rejects, discards, or otherwise reconfigures some components. Finally, one may fully understand the intended meaning of a text and choose to interpret it within an alternative framework. This is an oppositional, or resistant, reading. "One of the most significant political moments," Hall states, "is the point when events which are normally signified and decoded in a negotiated way begin to be given an oppositional reading," for this is when the struggle in discourse begins. The oppositional position, then, is most significant in terms of a viewer's agency because it entails the active interruption of hegemonic narratives on a small scale. The intended meanings of a text, Hall explains, "are hegemonic precisely because they represent definitions of situations and events which are 'in dominance.'" Importantly, the intended meanings carry with them "the stamp of legitimacy" to appear as natural, inevitable, or otherwise ordinary. ${ }^{39}$ Consider, for example, the ways in which Google imbues its homepage and search results with a sense of legitimacy through its single search box and streamlined pages of ten search results at a time. Google thus takes almost all complexity out of the search process so 
that individuals are presented with a single interpretation of the Web, positioned as entirely ordinary and natural.

Hall's three positions constitute the primary ways of interpreting a given text. As summarized by Judith Mayne, "The dominant reading is one fully of a piece with the ideology of the text, while the negotiated reading is more ambivalent . . . The oppositional reading, then, is one totally opposed to the ideology in question." ${ }^{40}$ Hall's theory of oppositional reading was later adopted by Manthia Diawara and bell hooks, each of whom applies the concept to African American spectatorship in relation to American films representing dominant ideologies. Both authors consider the potential for resistance within African American spectatorship, with Diawara primarily interested in resistant spectatorship as an act of anti-identification with racist representations, and hooks considering the topic from the position of African American female film lovers that incorporates feminist thought into theories of resistant spectatorship.

Though Hall outlines the general ideas, the term resistant spectatorship was formulated and explored by Manthia Diawara in 1988 in a discussion of differences between African American and white American spectatorship and identification. Diawara argues that spectators are "socially and historically as well as psychically constituted." 41 Viewers bring their own personal and cultural histories with them when they engage with film. Diawara's analysis is based in the resistant spectatorship of African American audiences and looks at the refutation of stereotypical portrayals and symbolic violence toward African Americans in popular Hollywood films such as The Color Purple (1985) and 48 Hrs. (1982). Diawara sees independent film as offering an alternative to dominant modes of filmmaking and destructive representation. ${ }^{42}$

The feminist author bell hooks explores the "oppositional gaze" in relation to African American women spectators in her collection of essays titled Black Looks: Race and Representation, stating that this defiant action both draws the individual's attention to the oppressive social field and offers the possibility of agency. Through the application of a black feminist perspective to Diawara's formulation of resistant spectatorship, hooks argues that African American female spectators do more than resist, they "create alternate texts that are not solely reactions ... As critical spectators, Black women participate in a broad range of looking relations, contest, resist, revise, interrogate, and invent on multiple levels." ${ }^{43}$ Thus, hooks contributes a necessary revision of Diawara's resistant spectatorship, one recognizing that a viewer does not act either fully in compliance with or in opposition to a text and instead has "the ability to manipulate one's gaze in the face of structures of domination that would contain it." 44 In talking with African American women who love film, even mainstream movies in line with dominant ideologies, hooks finds that these women consciously resisted identifying with the films. An understanding and awareness of the politics of race and racism, hooks states, enables individuals to be oppositional or resistant readers of dominant messages..$^{45}$

From its introduction in the 1970s until the present, oppositional or resistant spectatorship has undergone a great deal of discussion and critique within the field of film studies. Yet this theory has much to offer in terms of considering how individuals approach other forms of media in our information-saturated society, including, and perhaps especially, online information. Resistant spectatorship is a useful frame for analyzing how not only film but also media structures and related phenomena are received. Applied 
to the realm of libraries and information literacy, it reveals that the library profession's traditional decontextualized and skills-based approach to IL negates the inherently political and social nature of information. Such an approach to information literacy results in a lack of engagement with the complexities intrinsic to contemporary information sources. The theory of resistant spectatorship reminds the library profession that hegemonic information structures can and should be read along oppositional resistant lines. The following section will examine information literacy more closely and propose an understanding of IL conducive toward resistant readings of information.

\section{Critical IL and Resistant Readings}

Information literacy is a concept adopted by and of importance to the library profession since the 1980s that is akin to other types of literacy developed in response to changing modes of communication, such as digital, media, and visual literacies. Library professionals have largely conceived of and identified IL as the set of abilities required to effectively locate, evaluate, and use information for a particular need. However, such widely accepted definitions of IL fail to account for the fact that information literacy is a contested and circumstantial term, entirely subject to interpretation. In an examination of three theoretical understandings of the concept of information literacy, Louise Limberg, Olof Sundin, and Sanna Talja describe IL as "purposeful information practices in a society characterized by an almost limitless access to information and where information practices in digital environments shape and constitute important elements in most people's lives in our part of the world." 46 The term information signifies both the content and the physical object that carries this content, while literacy includes not just reading and writing but also a number of other actions that relate to understanding and evaluating texts. Importantly, information literacy is a challenged term that can be interpreted in numerous ways, depending upon the theoretical perspective from which it is viewed as well as the particular institutions and social settings within which it occurs. Christine Pawley demonstrates the inherent tension between these two terms, noting, "'Information literacy' is indeed an activity greater-or at least different than —-the sum of its parts" in that information signifies control while literacy connotes democratic empowerment. This tension can be a productive one because it provides an opportunity for librarians to "be explicit about the moral and political commitment to flattening rather than reinforcing current information and literacy hierarchies." 47

Instead of embodying a productive tension, information literacy in the United States solidified into a set of national standards to be adopted largely for accreditation and assessment purposes. The discourse of IL largely concerns the acquisition of skills, in particular a set of competencies practiced in a library or online setting. Attempts at a broader understanding of information resources and the roles they play are largely ignored in favor of more discrete and compartmentalized skills, such as knowing how to retrieve peer-reviewed journal articles from a library database. Information literacy posits different means of accessing content as neutral-including the library, search engines, and subscription databases. It assumes that one only needs to know where to look to meet an information need and apply a checklist to the source. A brief consideration of IL's development will illustrate how the concept came to be realized as an apolitical 
and decontextualized practice instead of a resistant one, as proposed by Cees Hamelink around the time the term was first presented.

Information literacy has undergone much analysis since being introduced in the 1970s. The first appearance of the term information literacy did not originate in the

Attempts at a broader understanding of information resources and the roles they play are largely ignored in favor of more discrete and compartmentalized skills, such as knowing how to retrieve peer-reviewed journal articles from a library database. educational domain but instead in the industrial sector. Paul Zurkowski's 1974 report describes the need for governmental organizations in the United States to develop business and workplace information competencies in its citizens, as well as the skills these employees require to operate in the rapidly expanding information services industry ${ }^{48}$ Zurkowski's original conception of information literacy is rooted in an environment where the private sector takes primary responsibility to produce both information and IL skills in the populace.

Since Zurkowski's coining of the term, it has been widely adopted by educational institutions and has become of central importance to academic librarians, and this original inception of the term has played a significant part in defining IL as it exists today.

A lesser-known paper written soon after Zurkowski's by Cees Hamelink takes a very different approach to information literacy. Hamelink's conception of IL, described in 1974, posits it as a mind-set to be developed by individuals to counter the effects of content provided by hegemonic forces, as opposed to a characteristic to be cultivated in large populations so that they may more effectively function within society to maintain existing conditions. ${ }^{49}$ The political nature of information literacy is made explicit from the outset of Hamelink's paper, in which he states, "A new 'information literacy' is necessary for liberation from the oppressive effects of the institutionalized public media." ${ }^{50}$ For Hamelink, the inchoate and fragmentary ways that information is presented and delivered result in it functioning as an oppressive tool that "keeps people from shaping their own world." The predigested nature of dominant information sources and the fact that they are selected and filtered by these same interests "preclude the insight of the world as something problematic and changeable." 51 This predigestion of information has continued to increase, evidenced by the development of corporate news bureaus responsible for bypassing the traditional media and creating "news" content using their own platforms and social media to create expertly polished advertisements appearing under the guise of news, also known as "native advertising."

Hamelink's notion of information literacy combined with information's intensifying commoditization and dissemination through corporate channels makes an alternative to the ways in which IL is conceived as a necessity if students are to learn how to navigate a complex information landscape. As a theory that places individuals' capacity to resist and reformulate the messages of dominant media at its center, resistant spectatorship offers a lens through which to view users' interactions with information more closely. It helps us oppose the common notion of a monolithic group that uncritically accepts information, whether using the library or online search engines, and consider a substitute 
to such easy interpretations of users' experiences with information. One understanding of information literacy in line with resistant spectatorship is that of critical information literacy, a theoretically informed approach to IL that addresses the political nature of one's engagement with information.

Critical information literacy takes issue with the assumptions of IL and the educational activities that take place in libraries. It engages such topics as the impossibility of pedagogical neutrality and the incompatibility of skills-based instruction with student engagement in the learning process. As a practice, critical information literacy considers how librarians can encourage students to engage with and act upon the power structures underpinning information's production and dissemination. Critical IL uses critical theory and critical pedagogy frameworks to analyze information literacy's norms and conventions, from its lack of involvement with the sociopolitical dynamics that shape scholarly information to the notion that IL is an educational obstacle that can be conquered. Among the first calls for critical information literacy is Allan Luke and Cushla Kapitzke's 1999 poststructuralist analysis of IL standards

Critical information literacy takes issue with the assumptions of IL and the educational activities that take place in libraries. It engages such topics as the impossibility of pedagogical neutrality and the incompatibility of skills-based instruction with student engagement in the learning process. and frameworks. They argue that current definitions of information literacy impose a generic and hierarchical approach to the subject when in fact the ambiguity, diversity, and multiplicity of information should be stressed. ${ }^{22}$ For James Elmborg, whose seminal 2006 article helped popularize critical information literacy in the profession, uncertainties regarding IL's meaning have resulted in a lack of clarity about its importance as well as the library's purpose in the academy. Toward this end, he proposes a critical information literacy that "provides a way for libraries to change [their] trajectory and more honestly align themselves with the democratic values that they invoke." 53 This recognition of the ways in which educational institutions-and by extension, libraries - act as cultural agents and enact dominant ideologies would have a wide range of implications for librarians and students alike.

Beyond recognition of and reflection upon such issues involving libraries and information, critical information literacy calls for action. It comprises a commitment to social justice that includes working to

Critical information literacy encourages librarians to develop an IL theory and practice that recognizes students' personal agency and attempts to create positive personal and social change. empower learners through their abilities to interrogate hierarchical systems such as white supremacy and patriarchy. Through this "process of questioning, and challenging the reliability and biases inherent in texts and other information sources," Lauren Smith states, people become aware of and able to act upon social justice issues. ${ }^{54}$ Critical information literacy encourages librarians to develop 
an IL theory and practice that recognizes students' personal agency and attempts to create positive personal and social change. ${ }^{55} \mathrm{~A}$ critical approach to information literacy education would entail a greater awareness of "each person's agency and ability to make meaning within the library setting," from teacher to student, an idea closely linked to that of the resistant spectator who makes meaning of texts according to their own historical and cultural identity.

As it is generally conceived in national standards and research, information literacy focuses upon commonalities among information practices and cultivating efficient information retrieval, making it difficult to develop an alternate formation of IL based upon more critical understandings. Alison Hicks notes that a critical approach to IL "moves beyond the narrow focus on dominant cultural information practices" by questioning the characteristics of global flows of information while developing "the learner's understanding of who she is (identity) and what she can do (agency)." 57 The goals of critical information literacy, then, might be seen as twofold: critical IL "engages learners with the broader social and cultural contexts of information questioning" while also fostering "a personal approach to learning, drawing from the learner's past experiences to develop their ability to critically construct, shape and negotiate knowledge, practices, and identities." ${ }^{58}$ The application of a critical information literacy perspective to Google Search will further illuminate what such an approach to IL entails.

The fundamentally democratic goals of libraries, as expressed in documents such as the American Library Association's "Core Values of Librarianship" statement and the Alexandria Proclamation on Information Literacy and Lifelong Learning, point to libraries' and information literacy's engagement with key issues surrounding corporate diffusion of information. These issues include privacy, intellectual freedom, and social responsibility. As members of a profession that must deeply understand how knowl-

Librarians occupy a unique space in the academy that arguably makes them best equipped to encourage students to interrogate the many forces behind information's access and use. edge and claims to truth are organized and evaluated, librarians occupy a unique space in the academy that arguably makes them best equipped to encourage students to interrogate the many forces behind information's access and use. In an exploration of Google Search as a site for critical examination and the development of students' transcultural competence, Hicks argues for the design of classes that encourage learners to understand the culturally specific dimensions of both information and their own practices. This means that students must understand not only their search results but also their search processes to see past the perceived universality of prevailing information sources such as Google. Google's position as a dominant content provider makes it imperative that students comprehend that the positioning of Google and its results as "objective" is the outcome of a great deal of political and social manipulation, not least of which is Google's own insistence on the impartiality of the search engine's algorithm. As the starting point for a vast majority of personal and academic research, search engines are media objects ripe for classroom critique. Because searches shape both how we access viewpoints and how our own perspectives are formed, it is essential to 
recognize, Hicks says, that "the parameters that humans set for indexing or algorithmic ranking mean explicit editorial choices are made ... At the same time, Google defends these ranking and indexing choices as an objective reflection of reality." 59 The teaching of discrete search skills in library and subscription resources sidelines issues of commercialization, which have a much greater impact on how information is received. A critical approach to IL, in particular one informed by the theory of resistant spectatorship, helps reveal these issues.

\section{Conclusion}

As applied to information and information literacy, resistant spectatorship encourages a reconceptualization of library instruction and argues for the necessity of acknowledging the variety of contexts within which learners operate on a personal level. As Elmborg notes, library researchers "tend to separate students from economic and social contexts, thereby detaching them from school, teacher, and society," while in actuality we need to develop a greater understanding of "how individual students in specific contexts and communities encounter information generally and the library specifically." 60 Information, whether in the library setting or apart from it, is never encountered on generalizable and

If we accept that information is not neutral, we can also acknowledge that any encounter with information is similarly imbued with social and cultural dimensions. depoliticized terms. If we accept that information is not neutral, we can also acknowledge that any encounter with information is similarly imbued with social and cultural dimensions. Resistant spectatorship asks us to consider these positions, and how individuals resist and reconfigure dominant information sources. Additionally, resistant spectatorship contributes to the further development of, as Henry Blanke states, "a critical discourse of librarianship [that] would provide us with a language and analytical framework with which to critique the promotion, both within and without the library profession, of information as a commodity." 61

Schiller observed in 1996 that public organizations, and in particular libraries-“long-standing custodian[s] of the idea and practice of information as a social good"are being redefined and stripped of their social character through the extensive commoditization of

Understanding and being able to promote resistant readings will be key to educating individuals who do not merely know how to find the right information to complete an assignment or carry out a task, but who also understand how to effectively interrogate and oppose the information that they encounter. information by private interests. ${ }^{62}$ As search engines function increasingly as highly profitable tools that translate information needs into consumption, one possibility for resistance is based in personal conceptions of information guided by resistant spectatorship and put into practice at 
libraries using a critical information literacy approach. Understanding and being able to promote resistant readings will be key to educating individuals who do not merely know how to find the right information to complete an assignment or carry out a task, but who also understand how to effectively interrogate and oppose the information that they encounter. Furthermore, a critical approach to IL and the work that libraries do will enable them to better function as organizations committed to the public good rather than the status quo.

The obstacles to such a realization are many and range from a lack of knowledge among librarians regarding how to incorporate critical information literacy into the constellation of their practices, to structural and organizational barriers, to the increasing corporatization of higher education. The primary challenge to critical information literacy and developing a fully realized critical perspective, Troy Swanson argues, lies not in convincing faculty members, administrators, or professional organizations of its importance but instead in "convincing our students by shifting the focus of critical pedagogy toward student belief about knowledge and worldview." ${ }^{63}$ This perspective, which I share, holds that interactions with information are highly personal, value-laden, and intertwined with belief. Swanson notes the interconnectedness among information, belief, and communities or societies. He encourages librarians developing a critical approach to information literacy to "form avenues of instruction that get students to recognize the beliefs they hold and how those beliefs impact their view of information sources." ${ }^{64}$ Such instruction, then, would ask questions central to how students know what they know, as well as how certain voices are privileged over others and how search engines and other content providers participate in this system of dominance and oppression.

Information literacy, like spectatorship, Elmborg says, "is in constant flux and embedded in cultural situations, each situation nuanced and different from others." ${ }^{65}$ Critical information literacy, like resistant spectatorship, involves the ability to critically interpret a text or even an entire system with which one engages. Both approaches, whether to IL or media, demand the recognition of individuals' agency and power and emphasize the capacity we hold to create change, even in the face of seemingly insurmountable challenges. Both approaches make the consideration of power relations, corporate domination, and stratification that we contend with in society central to understanding how information is created, received, and used. The challenge is to create learning environments that empower students to define their education and create change on their own terms - a considerable task requiring great effort and understanding, but not an impossible one using concepts such as resistant spectatorship and critical information literacy to guide our everyday work. Most importantly of all, this work is possible only when we do it with the help of one another.

Eamon Tewell is a reference and instruction librarian and assistant professor at Long Island University in Brooklyn, New York; he may be reached by e-mail at: eamon.tewell@liu.edu.

\section{Notes}

1. Siva Vaidhyanathan, The Googlization of Everything (Berkeley: University of California Press, 2011), 205-6. 
2. Henry T. Blanke, "Libraries and the Commercialization of Information: Towards a Critical Discourse of Librarianship," Progressive Librarian 2 (1991): 9-14.

3. Michael Zimmer, "The Gaze of the Perfect Search Engine: Google as an Infrastructure of Dataveillance," in Web Search: Multidisciplinary Perspectives, ed. Amanda Spink and Michael Zimmer (Berlin: Springer-Verlag, 2008), 77-99.

4. Safiya Umoja Noble, "Google Search: Hyper-Visibility as a Means of Rendering Black Women and Girls Invisible," in "Blind Spots," special issue, InVisible Culture 19 (Fall 2013).

5. Amber Davisson, "Google Search and the Development of Public Opinion," Journal of Digital and Media Literacy 1, 2 (Winter 2013), http:/ / www.jodml.org/2013/12/01/ googlesearch-and-the-development-of-public-opinion/.

6. Herbert I. Schiller, Information Inequality: The Deepening Social Crisis in America (New York: Routledge, 1996), 45.

7. Ibid., 44 .

8. Ibid., 46.

9. Safiya Umoja Noble, "Missed Connections: What Search Engines Say about Women," bitch: Feminist Response to Pop Culture 54 (Spring 2012): 36-51.

10. Eli Pariser, The Filter Bubble: What the Internet Is Hiding from You (New York: Penguin, 2011).

11. Alison Hicks, "Knowledge Societies: Learning for a Diverse World," in Not Just Where to Click: Teaching Students How to Think about Information, ed. Troy A. Swanson and Heather Jagman (Chicago: Association of College and Research Libraries, 2015), 217-42.

12. Emily Drabinski, "Teaching the Radical Catalog," in Radical Cataloging: Essays at the Front, ed. K. R. Roberto (Jefferson, NC: McFarland, 2008), 198-205.

13. Tarleton Gillespie, "The Relevance of Algorithms," in Media Technologies: Essays on Communication, Materiality, and Society, ed. Tarleton Gillespie, Pablo J. Boczkowski, and Kirsten A. Foot (Cambridge, MA: MIT Press, 2014), 167-94.

14. Noble, "Google Search: Hyper-Visibility."

15. Gillespie, "The Relevance of Algorithms."

16. Ibid.

17. Noble, "Missed Connections," 39.

18. Bess Sadler and Chris Bourg, "Feminism and the Future of Library Discovery," in "Diversity in Library Technology," special issue, Code4Lib Journal 28 (April 2015).

19. Davisson, "Google Search."

20. Kristen Purcell, Joanna Brenner, and Lee Rainie, "Search Engine Use 2012" (Washington, DC: Pew Research Center, Pew Internet \& American Life Project, 2012), http:/ / www. pewinternet.org/2012/03/09/search-engine-use-2012/.

21. Alejandro Diaz, "Through the Google Goggles: Sociopolitical Bias in Search Engine Design," in Spink and Zimmer, Web Search, 11-34.

22. Noble, "Missed Connections," 39-40.

23. Zimmer, "The Gaze of the Perfect Search Engine," 77.

24. Ibid.

25. Ibid., 86 .

26. Ibid., 92.

27. Vaidhyanathan, The Googlization of Everything, 7.

28. Paul Baker and Amanda Potts, “'Why Do White People Have Thin Lips?' Google and the Perpetuation of Stereotypes via Auto-Complete Search Forms," Critical Discourse Studies 10, 2 (May 2013): 187-204.

29. Noble, "Google Search: Hyper-Visibility."

30. Vaidhyanathan, The Googlization of Everything, 182.

31. Noble, "Google Search: Hyper-Visibility."

32. Latanya Sweeney, "Discrimination in Online Ad Delivery," Communications of the ACM [Association for Computing Machinery] 56, 5 (May 2013): 44-54.

33. Baker and Potts, “'Why Do White People Have Thin Lips?" 200. 
34. Davisson, "Google Search."

35. Vaidhyanathan, The Googlization of Everything, 201.

36. Cathy Eisenhower and Dolsy Smith, “The Library as 'Stuck Place': Critical Pedagogy in the Corporate University," in Critical Library Instruction: Theories and Methods, ed. Maria T. Accardi, Emily Drabinski, and Alana Kumbier (Duluth, MN: Library Juice Press, 2010), 305-18.

37. Bernard Stiegler, Symbolic Misery, Volume 1: The Hyperindustrial Epoch (Cambridge, U.K.: Polity, 2014).

38. Stuart Hall, "Encoding, Decoding," in The Cultural Studies Reader, ed. Simon During (London: Routledge, 1999), 90-103.

39. Ibid., 102-3.

40. Judith Mayne, Cinema and Spectatorship (New York: Routledge, 1993), 92.

41. Manthia Diawara, "Black Spectatorship: Problems of Identification and Resistance," Screen 29, 4 (September 1988): 66-76.

42. Ibid., 75-76.

43. bell hooks, "The Oppositional Gaze: Black Female Spectators," in Black Looks: Race and Representation (Boston: South End Press, 1992), 115-31.

44. Ibid., 116.

45. Ibid., 126.

46. Louise Limberg, Olof Sundin, and Sanna Talja, "Three Theoretical Perspectives on Information Literacy," Human IT 11, 2 (2012): 93-130.

47. Christine Pawley, "Information Literacy: A Contradictory Coupling," Library Quarterly 73, 4 (2003): 422-52.

48. Paul G. Zurkowski, "The Information Service Environment Relationships and Priorities: Related Paper No. 5," National Commission on Libraries and Information Science, National Program for Library and Information Services, November 1974, http:/ / eric. ed.gov / ?id=ED100391.

49. Andrew Whitworth, Radical Information Literacy: Reclaiming the Political Heart of the IL Movement (Oxford, U.K: Elsevier, 2014).

50. Cees Hamelink, “An Alternative to News," Journal of Communication 26, 4 (December 1976): $120-23$.

51. Ibid., 120.

52. Allan Luke and Cushla Kapitzke, "Literacies and Libraries: Archives and Cybraries," Pedagogy, Culture \& Society 7, 3 (1999): 467-91.

53. James Elmborg, "Critical Information Literacy: Implications for Instructional Practice," Journal of Academic Librarianship 32, 2 (March 2006): 192-99.

54. Lauren Smith, "Towards a Model of Critical Information Literacy Instruction for the Development of Political Agency," Journal of Information Literacy 7, 2 (2013): 15-32.

55. Ibid.

56. Elmborg, "Critical Information Literacy," 194.

57. Hicks, "Knowledge Societies," 218.

58. Ibid., 220.

59. Ibid., 220-21.

60. Elmborg, "Critical Information Literacy," 194.

61. Blanke, "Libraries and the Commercialization of Information," 12-13.

62. Schiller, Information Inequality, 35.

63. Troy Swanson, "Information Is Personal: Critical Information Literacy and Personal Epistemology," in Accardi, Drabinski, and Kumbier, Critical Library Instruction, 265-77.

64. Ibid., 271.

65. Elmborg, "Critical Information Literacy," 195. 